\title{
INSCRIÇÕES LATINAS DA PROVÍNCIA ROMANA DA BRETANHA
}

\author{
PEDRO PAULO ABREU FUNARI* \\ Instituto de Filosofia e Ciências Humanas \\ Universidade Estadual de Campinas \\ RENATO PINTO** \\ Instituto de Filosofia e Ciências Humanas \\ Universidade Estadual de Campinas
}

\section{Apresentação}

A província romana da Bretanha produziu, a partir, 43 d.C. uma grande quantidade de inscrições, ainda pouco difundidas no vernáculo, motivo pelo qual apresentamos algumas delas vertidas para nossa língua. A escolha foi bastante subjetiva e não pretende, de modo algum, ser representativa. Um critério foi, de todo modo, determinante: a extensão e inteligibilidade das epígrafes. Procuramos, nas versões, atualizar o linguajar, motivo pelo qual utilizamos, via de regra, a terceira pessoa, usual no coloquial brasileiro, para transpor a segunda pessoa do original latino, assim como mesclamos terceira e segunda pessoas, como na língua falada no Brasil. Do mesmo modo, ao lado de alguns termos técnicos inevitáveis, preferimos, sempre que possível, aproximações com o uso vernacular contemporâneo.

Inv.nos.29+31. Bowman 1983: 128 .

[ ] Crispino suo [ ?

[Grattio Crispino redeunte .[...

[ ] [[non fui mihi]] et .d.[..

[ li]benter amplexus s[um do-

mine salutandi te occassionem

[d] ominum meum et quem saluom
Para Crisipo. Grácio Crisipo está voltando para ... e ... eu, alegremente, meu senhor, aproveitei a ocasião para te saudar. Meu senhor, saúdo-o e faço votos para que suas esperanças se realizem.

* Professor Titular de História Antiga do Departamento de História do IFCH/Unicamp e Coordenador do Núcleo de Estudos Estratégicos (NEE/Unicamp).

** Bacharel em História e Mestre em Arqueologia pela USP, doutorando em História da Unicamp, pesquisador do Núcleo de Estudos Estratégicos (NEE/Unicamp) e bolsista da FAPESP. 
[[habere]] esse et omnis spei

[[suae]] compotem inter praecipua uoti habeo. hoc enim de

me semper meruisti usque

ad hanc $\mathrm{d}[\mathrm{]}$ tem. cuius fid-

ucia ho[ ]e te primum [

[ ]..[ ]. c 'ut' ..e il [...

[.....]m Marcellum clarissi[mum ui-

[rum] consularem meum. quar. [....

[oc]cassionem nunc ut [

[ ] tibi amicorum do[

sua $[\mathrm{p}]$ resentia. quos tu[

illius scio plurimos habere [....

quomodo uoues. imple quidq[uid

de te exspecto et me .lu [.]...

amicis ita instrue ut beneficio

tuo militiam [po]ssim iucundam

experiri. ha[ec ti]bi a Vindolan-

da scribo .[ ] hiberna

[. ].n. u. h.. [ ].ius a.[

deae Suli Minerv(a)e Soli-

nus dono numini tuo ma-

iestati paxsa $(\mathrm{m})$ ba $(\mathrm{ln})$ nearem et [pal-

leum [nec p]ermitta[s so]mnum

nec san[ita] tem <.> ei qui mihi fr(a)u-

dem [f]ecit si uir si femi[na] si seruus

s[i] 1[ib]beri sui uel son sua e[t?] qui

[.].[ ]... ] ]deg...[

ei quoque [ ]xe [

[ so]mnum ne[c sanitate-

m [ ]n[ p]al $<\mathrm{u}>1[\mathrm{e}] \mathrm{um}$

et reli $<\mathrm{n}>\mathrm{q}$ [ua]s nissi ad [te]mplum tu-

um istas res retulerint

domine Neptune

t(i)b(i) d(o)no (h)ominem qui
Pois sempre mereceu isto de mim, até

hoje em dia, quando ocupa alto cargo. No que depende disso ... o senhor primeiro...

Lúcio Marcelo, esse homem muito distinto, meu governador. Ele, portanto, oferece agora a oportunidade de ... os talentos de teus amigos por meio da presença dele. Entre aqueles que o senhor assiste com a permissão dele, muitos, eu sei, tiveram o que lhes prometeu.

Conceda-me o que espero do senhor ... então, apresente-me amigos, e que graças ao senhor eu possa ter um bom período de serviço militar. Escrevo esta carta de Vindolanda, onde estão meus acampamentos de inverno, de forma que $\ldots$

32- Roubo de uma capa e túnica de banho. Inv.no.616. Tomlin 1988: 150.

Solino para a deusa Súlis Minerva. Ofereço à tua divindade e majestade minha capa e túnica de banho. Não permita que tenha sono ou saúde aquele que me enganou, seja homem ou mulher, seja escravo ou livre, a menos que se apresente e traga tais bens ao seu templo ... os filhos dele ou seus ... e, quem ... para ele, também, ... sono ou saúde ... capa e o restante, a menos que tragam tais coisas ao teu templo.

Hamble Estuary (ST 48 08) (fig. I e pl. xxxviii). Tomlin 1997: 457.

Senhor Netuno, eu te ofereço o homem que roubou a grana e as seis pratas de 
(solidum) inuolau[it] Mu-

coni et argenti[olo]s

sex. ide(o) dono nom(n)a

qui decepti, si mascel si

femina, si puuer si puue-

1la. ideo dono tibi, Niske,

et Neptuno uitam, uali-

tudinem, sanguem eius

qui conscius fueris eius

deceptionis. animus

qui hoc inuolauit et

qui conscius fuerit ut

eum decipias. furem

qui hoc inuolauit sanguem

eiius consumas et de-

cipias, domin[e] $\mathrm{Ne}[\mathrm{p}]$

tune.

i

Octauius Candido frati suo salutatem

a Marino nerui pondo centum

explicabo e quo tu de hac

re scripseras ne mentionem

mihi fecit aliquotiens tibi

scripseram spicas me emisse

prope $\mathrm{m}$ (odius) quinque milia prop-

ter quod (denari) mihi necessari sunt

nisi mittis mi aliquit (denariorum)

ii

minime quingentos futurum

est ut quod arre didi perdam

(denarios) circa trecentos et erubes-

cam ita rogo quam primum aliquit

(denariorum) mi mitte coria que scribis

esse Cataractonio scribe

dentur mi et karrum de quo

scribis et quit sit cum eo karro

mi scribe iam illec petissem

nissi iumenta non curaui uexsare
Mucônio. Então, dou os nomes de quem

levou essas coisas, seja homem ou

mulher, seja menino ou menina. Então, te

ofereço, Nisco e a Netuno a vida, saúde e

o sangue daquele que está ciente dessa

tramóia. Que possam tomar o ânimo de

quem roubou e de quem está ciente.

Senhor Netuno, consuma e leve embora o sangue do ladrão que fez o roubo.

32- Carta de Otávio para Cândido (Tab.

Vindol. ii 343) plate viii. Bowman 1994:

\section{6-7.}

Otávio saúda seu mano Cândido.

Darei conta das cem libras de nervuras de Marino. Desde que você escreveu sobre isso, ele não fez menção do assunto para mim. Escrevi para você várias vezes que comprei por volta de cinco mil módios de espigas de grão, para as quais preciso de dinheiro. A não ser que me envie algum dinheiro, ao menos quinhentos denários, o resultado é que perderei o que dei como depósito, uns trezentos denários, e passarei vergonha. Então, peço que mande dinheiro logo. As peças de couro bovino sobre as quais escreveu estão em Cataractônio - escreva para que me sejam dadas, e a carroça sobre a qual escreveu. E fale o que se passa com aquela carroça. Eu já devia ter ido até lá para pegá-las, mas não quis machucar os animais nas estradas ruins. Fale com Tércio sobre os 
dum uiae male sunt uide cum Tertio

de (denariis) viii s(emisse) quos a Fatale accept

non illus mi [ ] accepto tulit

iii

scito mae explesse [[exple]] coria

clxx et bracis excussi habeo

$\mathrm{m}$ (odios) cxix fac (denarios) mi mittas ut possi-

$\mathrm{m}$ spicam habere in excusso-

rio iam autem si quit habui

perxcussi contuber-

nalis Fronti amici hic fuerat

desiderabat coria ei ad-

signarem et ita (denarios) datur-

$\{u r\}$ us erat dixi ei coria in-

tra K(alendas) Martias daturum Idibus

iv

Ianuariis constituerat se uentur-

um nec interuenit curauit

accipere cum haberet coria si

pecuniam daret debam ei Fronti-

nium Iulium áudio magno lice-

re pro coriatione quem hic

comparauit (denarios) quinos

saluta Spectatum I...-

rium Firmum

epistulas a Gleucone accepi ual (e)

Uindol oito denários e meio que ele recebeu de Fatal. Ele não os repassou para mim. Saiba que completei as cento e setenta peças de couro e que tenho cento e dezenove módios de grãos debulhados. Não deixe de me mandar dinheiro para que eu possa por as espigas de grão no terreiro de debulhar. Além do mais, já debulhei tudo o que tinha. Um companheiro de caserna do teu amigo Fronto esteve aqui. Ele queria que fornecesse as peças de couro de boi, e, se fizesse isso, estaria pronto para dar-me o dinheiro. Disse a ele que as entregaria até as calendas de março. Ele decidiu que viria nos idos de janeiro. Não apareceu e nem se deu ao trabalho de obtê-las, porque já tinha peças de couro. Se ele tivesse dado o dinheiro, eu as teria entregado para ele. Soube que Frontino Júlio pôs a venda, por alto preço, produtos de couro que comprou por cinco denários a unidade.

Mande lembranças a Espectato e ... e

Firmo. Recebi as cartas de Glauco.

Saudações.

(entregar) em Vindolanda.

33- Apelo ou petição (Tab. Vindol. ii

344). Bowman 1994: 138-9.

eo magis me ca[ ]

d...[ ] em mercem [ ]

r[..] uel effunder[ ]r[

[..]mine probo tuam maies-

[t]atem imploro ne patiaris me

[i]nnocentem uirgis cas[t]igatum

esse et domine prou[ ] prae-

[fe]cto non potui queri quia ua-

[let]udini detinebatur

ques[tu]s sum beneficiario ...ele mais ainda me bateu...bens...ou jogá-los no ralo. Como cabe a um homem honesto, imploro à sua grandeza que não permita que eu, um homem inocente, seja espancado com varas e, meu senhor, uma vez que não pude reclamar com o prefeito do acampamento porque ele estava detido pela doença, reclamei, em vão, com o soldado beneficiário e com o resto dos centuriões de sua unidade. Imploro 
ii

[ ce]nturionibu[s

[ ] numeri eius [

[ tu]am misericord[ia]m

imploro ne patiaris me

hominem transmarinum

et innocentem de cuius f[ide

inquiras uirgis cruent[at] $\mathrm{u}$ [um

esse ac si aliquid sceler[i]s

commississem

i

Masclus Ceriali regi suo salutem

cras quid uelis nos fecisse

rogó dómine prae-

cipias utrum[n]e

cum uexsilló . omnes

rediemus an alter-

ni c.....rum . aeque

ii

(faltam duas linhas)

felicissim[u]s [

et sis mihi propitius

(espaço de uma linha)

ceruesam commilitones

non habunt quam

rogó iubeas mitti

F[1]auio Ceriali praef(ecto)

(espaço de uma linha)

a Masclo dec(urione)

\section{i}

Maior Maritim[o] s[uo] salutem

scire te uolui epistulas mihi mis-

sas esse ab patri meó in qui-

bus scribit mihi ut ei no-

tum faciam quid gesseró de

fussá quod si itá gessisti

negotium cum caesaria-

nis fac ut certum mihi

[r]e[s]scribas ut egó pa[tri por sua misericórdia, para que não permita que um homem de além mares e inocente - sobre cuja boa fé pode inquirir - seja sangrado por varas como se tivesse cometido algum crime.

Inv.no.93.1544. Bowman 1996: 324.

Masclo para Cereal, seu rei. Saudações!

Por favor, senhor, dê-me instruções sobre

o que quer que façamos amanhã.

Devemos retornar com o usual ou uma outra opção?...muito feliz e muito bem disposto para comigo. Meus

companheiros soldados não têm cerveja. Por favor, peço que solicite o envio de uma remessa.

(verso)

Para Flávio Cereal, prefeito do acampamento, de Masclo, decurião.

Inv.no.91.1022. Bowman 1996: 326-7.

Maior para seu caro Marítimo.

Saudações!

Queria deixá-lo a par das cartas que recebi de meu pai pedindo-me que explique o que fiz em relação à peça do moedor. Sobre isso, se você negociou algo com os soldados cesarianos, escreva-me com informações claras para que possa, então, escrever para meu pai. 
ii

meo sic resscribere

possim si quid inter-

numeraueris ego tibi

sine morá bracem ex-

pellam pro s\{[.]\}ummá

quod efficaitur egó

cum haec tibi scribe-

rem lectum calfacieba $[\mathrm{m}$

opto sis felicissimu[s

salutat te pa[ter m]e[us

ual[e

[rogo s]i puerum missurus es mittes chir[o-

[grafum] cum eo quo securior sim

Uindolande

Coccelió Maritimó

[a Ma]i[o]re
Se fez algum pagamento como

intermediário, eu te enviarei trigo sem

demora na proporção do montante que

gastou. Que seja feito assim.

Enquanto escrevia esta carta para você, aquecia meu leito.

Espero que esteja muito feliz. Meu pai envia saudações. Saudações.

(margem esquerda)

Se enviar um jovem escravo emissário, por favor, mande uma nota de próprio punho com ele, para que eu fique mais seguro.

(verso)

Entregar em Vindolanda. Para Cocélio

Marítimo, de Maior.

RIB 292, 98-9.

[T(itus) F]laminius T(iti filius) Pol(lias tribu)

$\mathrm{Fa}[\mathrm{u}$ (entia) | [an] norum XXXXV

stip(endiorum) XXII mil(es) leg(ionis) | [XII]II

Gem(inae) militaui a(t)q(eu) nunc hic s[u]m |

[Hoc] legite et felices uita plus min[us] e[ste] :

[d]i uua uini et aqua prohibent, ubi $\mid \mathrm{Ta}[\mathrm{r}] \operatorname{tar}(\mathrm{a})$

aditis; uiuite, dum si[dus] | uitae dat tempus, honeste.
Tito Flamino filho de Tito, da tribo Pólia, de Faventia, quarenta e cinco anos de idade, com vinte e dois anos de serviço, soldado da XIV Legião Gemina. Servi como um soldado e agora, aqui estou. Leia isto e seja mais ou menos afortunado em sua vida. Os deuses proíbem as uvas do vinho e a água quando se entra no Tártaro.

Viva honestamente enquanto tua estrela te dá tempo para viver.

RIB 594, 199.

His terri tegitur | Ael(ia) Matrona quond(am) | uix(it) an(nos) XXVIII m(enses) II d(ies) VIII | et $M$ (arcus) Iul(ius) Maximus fil(ius) | uix(it) an(nos) VI m(enses) III d(ies) XX et Cam | pania Dub[i] tata $<$ e $>$ mater | uix(it) an(nos)
Cobertos por esta terra estão: ela, que certa vez foi Élia Matrona, e que viveu vinte e oito anos, oito dias. E Marcos Júlio Máximo, seu filho, que viveu seis anos, três meses e vinte dias. E Campânia 
L; Iul(ius) Maximus | s(ingularis) c(onsularis) alae Sar(matorum) coniux | coniugi incomparabili | et filio patri p[i]entissimo et socaere tena $\mid$ cissime memoria $(\mathrm{m}) \mathrm{p}$ (osuit).

\author{
Dubitata, sua mãe, que viveu cinqüenta \\ anos. \\ Júlio Máximo, tesoureiro sênior da ala dos \\ Samarcianos, seu marido, erigiu este \\ memorial para sua incomparável esposa, e \\ para seu filho, que foi extremamente \\ dedicado ao seu pai, e para sua mui tenaz \\ sogra.
}

\section{REFERÊNCIAS BibliográfiCAS}

BOWMAN, A. K. Life and Letters on the Roman Frontier: Vindolanda and its People. Londres: British Museum Press, 1994. 136 e 138-9.

BOWMAN, A. K.; THOMAS, J. D. New Writing-Tablets from Vindolanda. Britannia. v. 27, p. 299-328, 1996.

. Vindolanda: The Latin Writing-Tablets. Britannia Monograph Series No. 4. Londres: Society for the Promotion of Roman Studies, 1983.

COLLINGWOOD, R. G.; WRIGHT, R. P. The Roman Inscriptions of Britain. Oxford: Oxford University Press, 1965.

TOMLIN, R. S. O. II Inscriptions Monumental. Britannia. v. 28, p. 455-72, 1997. . The Curse Tablets. In: CUNLIFFE, B. (ed.). The Temple of Sulis Miverva at Bath, vol. II: The Finds from the Sacred Spring. Oxford: Oxford Committee for Archaeology: 1988. p. 59-277. 